\title{
KELIMPAHAN DAN KERAGAMAN JENIS IKAN FAMILI CHAETODONTIDAE BERDASARKAN KONDISI TUTUPAN KARANG HIDUP DI KEPULAUAN SPERMONDE SULAWESI SELATAN
}

\section{Abundance and Fish Diversity of Family Chaetodontidae Based on Live Coral Coverage Condition at Spermonde Island of South Sulawesi}

\author{
Nurjirana $^{1^{*}}$, Andi Iqbal Burhanuddin ${ }^{1}$ \\ Diterima: 5 Maret 2017 Disetujui: 28 Maret 2017
}

\begin{abstract}
The family Chaetodontidae known as butterflyfishes (kepe-kepe) is a species that associated with coral by consumes coral polyp as its feed. This study aimed to determine the abundance and fish diversity of Chaetodontidae and to look the relationship of fish Chaetodontidae abundance with live coral coverage at Spermonde Island. To determines the abundance and fish diversity of Chaetodontidae by using direct census, while to determine the condition of coral reel used line intercept transect (LIT) method. This study was conducted for 6 (six) station at Spermonde Island by collecting data on depth $4-6 \mathrm{~m}$ with 3 replicate in each station. Result of study found 5 genera and consist of 16 species fishes from family Chaetodontidae. The overall of Chaetodontidae found is $70 \mathrm{Ind} / 250 \mathrm{~m} 2$ with the largest abundance in Kapoposang island (46 Ind/250 m2) and the smallest is Karanrang island (1 Ind/250 m2). Percentage of live coral coverage on research station at Spermonde Island at "good" to "bad" categories highest coral coverage at Badi island (72.6\%) and the lowest is Balanglompo island (5\%). Fish diversity of Chaetodontidae is high at station that dominated by Acropora coral. Abundance and fish diversity of Chaetodontidae are no relationship significantly on the percentage of live coral coverage of research station at Spermonde Island.
\end{abstract}

Keyword : Chaetodontidae, coral reef, Spermonde.

\section{PENDAHULUAN}

Ikan Chaetodontidae merupakan salah satu organisme yang berhubungan langsung dengan terumbu karang dengan jumlah yang banyak dan merupakan kelompok ikan indikator pada ekosistem terumbukarang, selainpenyebarannya luas, keberadaannya juga dipengaruhi oleh kondisi terumbu karang. Eksploitasi ekosistem terumbu karang memberi pengaruh terhadap hewan asosiasi pada ekosistem terumbu karang termasuk ikan Chaetodontidae yang merupakan penghuni terumbu karang yang memanfaatkan polip karang sebagai makanannya.

Kepulauan Spermonde memiliki keanekaragaman jenis ikan karang yang bervariasi di setiap gugusan pulau-pulau dengan dominansi bentuk pertumbuhan dan kondisi fisik terumbu karang di setiap pulau yang berbeda, kondisi tersebut menyebabkan sebaran ikan karang khususnya kelompok indikator di Kepulauan Spermonde juga bervariasi. Hal tersebut yang

1 Departemen Ilmu Kelautan, Universitas Hasanuddin

* Nurjirana

Email: nurjirana@gmail.com mendasari perlunya dilakukan penelitian tentang kelimpahan dan keragaman jenis ikan famili Chaetodontidae dengan melihat pengaruh kondisi terumbu karang terhadap kelimpahan ikan famili Chaetodontidae di Kepulauan Spermonde. Penelitian ini bertujuan untuk mengetahui kelimpahan dan keragaman jenis ikan dari famili Chaetodontidae pada stasiun penelitian di KepulauanSpermonde, mengetahui kondisi terumbu karang serta melihat hubungan kelimpahan ikan Chaetodontidae dengan kondisi terumbu karang di setiap stasiun penelitian di Kepulauan Spermonde.

\section{METODE PENELITIAN}

Penelitian ini dilaksanakan pada bulan MeiJuli 2016 di enam Pulau (Pulau Balanglompo, Pulau Karanrang, Pulau Badi, Pulau LumuLumu, Pulau Lanjukang dan Pulau Kapoposang) di Kepulauan Spermonde, Kota Makassar, Sulawesi Selatan.

Penentuan stasiun penelitian dilakukan di tiga zona perairan yaitu inner zone, middle zone dan outer zone dengan melakukan pengambilan data 
ISSN: 2460-0156

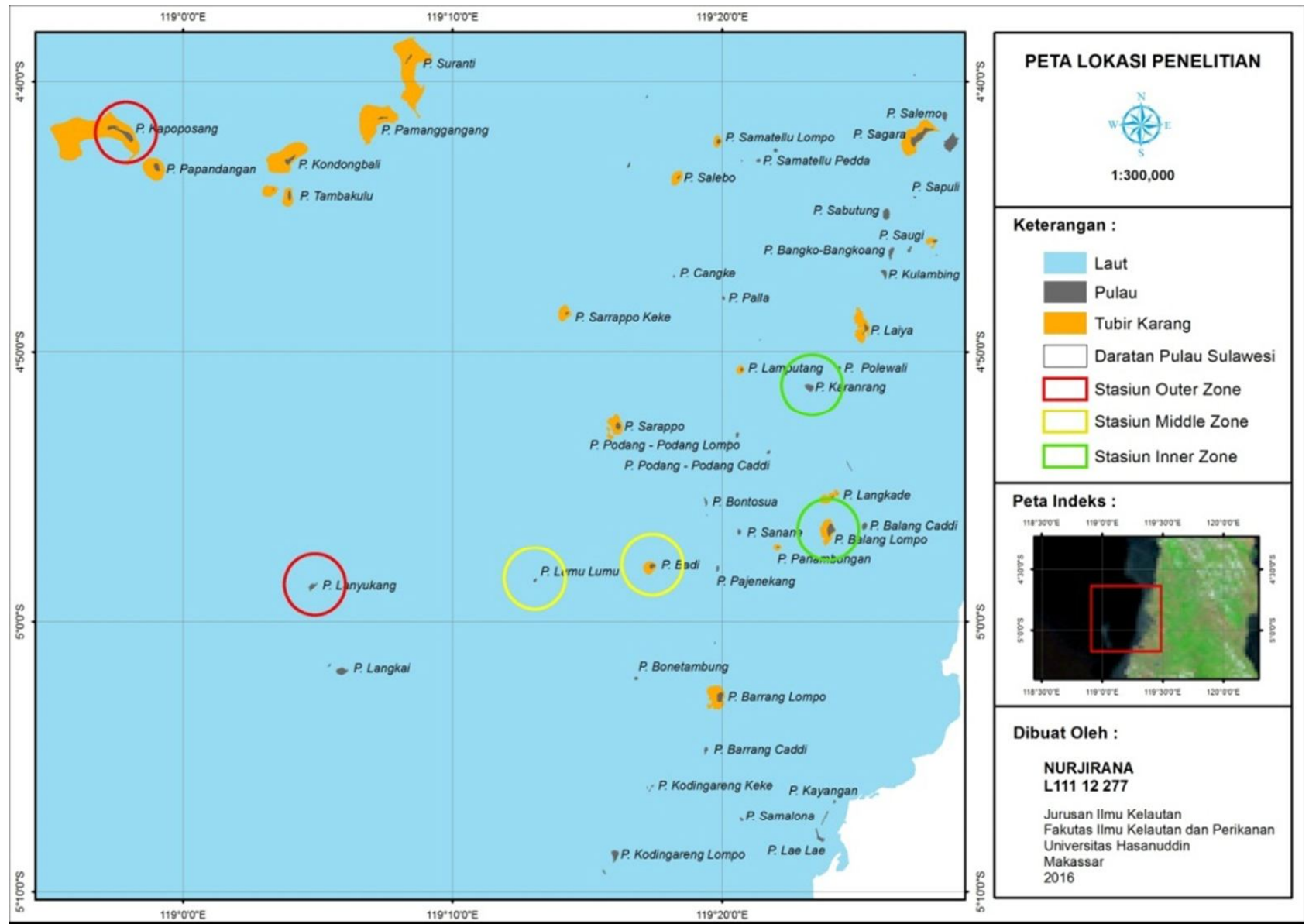

Gambar 1. Stasiun Penelitian

satu site di setiap stasiunnya, untuk mewakili ketiga zona perairan di Kepulauan Spermonde sebagai bahan pertimbangan, maka jumlah stasiun yang dipilih sebanyak enam stasiun penelitian. Untuk stasiun outer zone dilakukan di Pulau Kapoposang (Stasiun 1) dan Lanjukang (Stasiun 2), middle zone dilakukan di Pulau Badi (Stasiun 3) dan Pulau Lumu-Lumu (Stasiun 4), sedangkan inner zone stasiun pengambilan data dilakukan di Pulau Balanglompo (Stasiun 5) dan Pulau Karanrang (Stasiun 6).

Pengambilan data kondisi tutupan karang hidup pada stasiun di Kepulauan Spermonde dilakukan dengan menggunakan metode transek garis menyinggung atau Line Intercept Transect (LIT) dengan mengikut pada metode yang digunakan oleh English et al. (1994). Metode ini digunakan untuk menentukan kondisi substrat bentik terumbu karang berdasarkan pola bentuk pertumbuhan karang (Life form) dengan membentangkan tali transek (roll meter) sepanjang $50 \mathrm{~m}$ sejajar garis pantai (English et al.,1994). Adapun kategori substrat dasar diantaranya Hard Coral (HC), Soft Coral (SC), Dead Coral (DC), Dead Coral Algae (DCA),
Algae (A), Sponge (SP), Sand (S), dan Rubble (R).

Kelimpahan Ikan Chaetodontidae pada stasiun penelitian diukur dengan menggunakan metode pencacahan visual bawah air (Underwater Visual Sensus) berdasarkan English et al., (1994), cara kerja metode ini yaitu dengan memasang transek garis sepanjang $50 \mathrm{~m}$ dengan lebar area pemantauan seluas $5 \mathrm{~m}$ yaitu $2,5 \mathrm{~m}$ di sebelah kanan dan 2,5 m sebelah kiri transek, dan melakukan ulangan sebanyak tiga kali sehingga total luas area pengamatan seluas $250 \mathrm{~m}^{2}$.

Pengambilan data parameter lingkungan yang meliputi suhu, salinitas, $\mathrm{pH}$, dan kecepatan arus dilakukan setelah pengambilan data ikan dan karang sebagai parameter penunjang dalam melakukan penelitian.Pengukuran parameter tersebut dilakukan dengan menggunakan alat Water Quality Checker. Sedangkan untuk data kecepatan arus diukur dengan menggunakan layang-layang arus.

\section{Analisis Data}

Kelimpahan ikan menurut Odum (1971) dihitung dengan persamaan: 


$$
\mathrm{K}=\frac{\text { Jumlah ikan }(\text { ekor })}{\mathrm{K}=\text { Luas daerah }\left(150^{2}\right)}
$$

Kondisi terumbu karang dapat dilihat berdasarkan persentase penutupan karang hidup. Persentase penutupan karang hidup dihitung menurut persamaan English et al.(1994):

$$
\text { Persentase tutupan }=\frac{\text { Panjang tutupan kategori lifeform }-\mathrm{i}}{\text { Panjang total garis transek }} \times 100 \%
$$

\section{MDS (Multidimensional Scaling)}

Analisis multidimensional scaling merupakan output dari program PRIMER yaitu metode dalam analisis multivariat yang merepresentasikan (menggambarkan) sekumpulan data dalam sebuah peta untuk mengetahui faktor-faktor yang mempengaruhi suatu objek dan menggambarkan hubungan tersebut ke dalam grafik berdimensi (Clarke dan Warwick, 2001).

Adapun nilai stress value yang digunakan untuk mendeteksi akurasi nilai suatu plot yang menggambarkan struktur/komposisi spesies asli dengan struktur komposisi sampel yang didapat, yaitu:

1. Stress value $<0,05$ merupakan plot yang sempurna, dengan kemungkinan tidak ada kesalahan dalam menginterpretasikannya.

2. Stress value $=0,15$ menggambarkan plot yang cukup akurat dengan tingkat kesalahan interpretasi rendah.

3. Stress value $<0,2$ menggambarkan plot kurang baik untuk digunakan.

4. Stress value $>0,2$ sangat besar kemugkinan terjadi kesalahan dalam menginterpretasikannya (Clarke dan Warwick, 2001).

\section{ANOSIM (Analysis of Similarities)}

Analisis of Similarities merupakan analisis ragam pada aplikasi PRIMER 5 yang digunakan untuk mengetahui nilai signifikan dari sekelompok data yang diujikan (Clarke dan Warwick, 2001).

\section{SIMPER (Similarity of Percentage)}

Similarity of percentage merupakan output dari program PRIMER untuk mengetahui jenis organisme yang berkontribusi terhadap kesamaan (similaritas) dan perbedaan (disimilaritas) pengelompokan pada setiap stasiun pengamatan, yang didapatkan dari perbandingan nilai persentase kontribusi tiap- tiap jenis di dalam grup (ulangan) dan antar grup (stasiun) (Clarke dan Warwick, 2001).

Hubungan Tutupan Karang Hidup dengan Kelimpahan ikan Chaetodontidae dihitung dengan melakukan uji statistik korelasi spearman dengan persamaan sebagai berikut (Sudjana, 1996):

$$
\rho=1-\frac{6 \sum d^{2}}{n\left(n^{2}-1\right)}
$$

Keterangan:

$\rho=$ Koefisien korelasi Spearman

$\sum d^{2}=$ Total kuadrat selisih antar ranking

$n=$ Jumlah sampel penelitian

Hubungan tutupan karang hidup dan kelimpahan ikan dianalisis dengan menggunakan aplikasi SPSS 16.

\section{HASIL DAN PEMBAHASAN}

Jumlah ikan yang teramati pada stasiun di Kepulauan Spermonde sebanyak 70 individu yang terdiri dari 5 genera dan 16 spesies (tabel 1). Berdasarkan hasil uji statistik one way analysis of similarities (ANOSIM) menunjukkan nilai signifikan $0,007 \quad(p<0,05)$ yang berarti bahwa sebaran jenis ikan Chaetodontidae berbeda nyata di setiap stasiunnya.

Berdasarkan Tabel 1 menunjukkan kelimpahan tertinggi terdapat pada pulau Kapoposang dengan jumlah sebanyak 46 individu yang didominasi oleh jenis Hemitaurichthys polylepis yang hanya ditemukan pada daerah tebing Pulau Kapoposang dan jenis Hemitaurichthys polylepis umumnya ditemukan pada daerah tebing. Selain jenis tersebut ditemukan pula jenis Chaetodon kleinii hanya ditemukan pada stasiun Pulau Kapoposang, Pulau Lanjukang, Pulau Badi, dan Pulau Lumulumu dan hanya stasiun tersebut yang terdapat karang bercabang.

Jenis ikan Chaetodon kleinii memiliki ketertarikan terhadap karang bercabang baik sebagai area pemangsaan maupun sebagai tempat perlindungan, hal ini sesuai dengan Hukom (2001) yang menyatakan bahwa terjadi asosiasi antar Chaetodon kleinii dengan pertumbuhan karang bercabang di Pulau Karang Bangkok. Jenis ikan Chelmon rostratus yang merupakan pemangsa invertebrata hanya ditemukan pada Pulau Balanglompo dan Karanrang yang merupakan stasiun yang 
Tabel 1. Kelimpahan dan keragaman jenis ikan Chetodontidae pada stasiun penelitian di Kepulauan Spermonde.

\begin{tabular}{|c|c|c|c|c|c|c|c|c|}
\hline \multirow[b]{2}{*}{ Genus } & \multirow{2}{*}{$\begin{array}{l}\text { Jenis } \\
\text { Chaetodontidae }\end{array}$} & \multicolumn{7}{|c|}{ Stasiun Penelitian } \\
\hline & & $\begin{array}{l}\text { Kapo- } \\
\text { posang }\end{array}$ & $\begin{array}{l}\text { Lanju- } \\
\text { kang }\end{array}$ & Badi & $\begin{array}{l}\text { Lumu- } \\
\text { lumu }\end{array}$ & $\begin{array}{l}\text { Balang } \\
\text { Lompo }\end{array}$ & Karanrang & Jumlah \\
\hline \multirow{12}{*}{ Chaetodon } & C. trifascialis & 0 & 1 & 1 & 0 & 0 & 0 & 2 \\
\hline & C. kleinii & 3 & 1 & 1 & 2 & 0 & 0 & 7 \\
\hline & C. baronessa & 0 & 1 & 0 & 0 & 0 & 0 & 1 \\
\hline & C. octofasciatus & 0 & 0 & 4 & 0 & 0 & 0 & 4 \\
\hline & C. melanotus & 3 & 0 & 1 & 0 & 0 & 0 & 4 \\
\hline & C. trifasciatus & 2 & 0 & 1 & 0 & 0 & 0 & 3 \\
\hline & C. lineolatus & 0 & 0 & 1 & 0 & 0 & 0 & 1 \\
\hline & C. vagabundus & 0 & 0 & 1 & 0 & 0 & 0 & 1 \\
\hline & C. adiergastos & 0 & 0 & 0 & 0 & 1 & 0 & 1 \\
\hline & C. ornatissimus & 2 & 0 & 0 & 0 & 0 & 0 & 2 \\
\hline & C. punctatofasciatus & 2 & 0 & 0 & 0 & 0 & 0 & 2 \\
\hline & C. rafflesii & 2 & 0 & 0 & 0 & 0 & 0 & 2 \\
\hline Coradion & Coradion altivelis & 0 & 0 & 1 & 0 & 0 & 0 & 1 \\
\hline Chelmon & Chelmon rostratus & 0 & 0 & 0 & 0 & 6 & 1 & 7 \\
\hline Forcipiger & $\begin{array}{l}\text { Forcipiger } \\
\text { flavissimus }\end{array}$ & 2 & 0 & 0 & 0 & 0 & 0 & 2 \\
\hline Hemitaurichthys & $\begin{array}{l}\text { Hemitaurichthys } \\
\text { polylepis }\end{array}$ & 30 & 0 & 0 & 0 & 0 & 0 & 30 \\
\hline \multicolumn{2}{|c|}{$\begin{array}{l}\text { Jumlah Individu Chaetodontidae } \\
\text { Setiap Stasiun }\end{array}$} & 46 & 3 & 11 & 2 & 7 & 1 & 70 \\
\hline \multicolumn{2}{|c|}{$\begin{array}{l}\text { Jumlah Jenis Chaetodontidae Setiap } \\
\text { Stasiun }\end{array}$} & 8 & 3 & 8 & 1 & 2 & 1 & 16 \\
\hline
\end{tabular}

letaknya dekat dengan daratan dengan potensi mendapat masukan sedimen dari daratan yang cukup tinggi.

Menurut Allen et al. (1998) menyatakan bahwa hanya sedikit spesies yang berasosiasi dengan organisme yang hidup di dekatnya dimana pertumbuhan karang minimum. Terkecuali anggota genus Chelmon dan Parachaetodon Indo-Pasifik yang sering ditemukan di daerah karang pesisir bersedimen dimana keragaman karang rendah. Menurut Nontji (2005) yang menyatakan bahwa ikan Chaetodontidae biasanya ditemukan secara individual, berpasangan atau dalam kelompok kecil. Sumber makanan merupakan faktor penentu utama yang membedakan kehidupan sosial dan sistem pertemanan diantara ikan Chaetodontidae.

\section{Ekologi Ikan Famili Chaetodontidae}

Berdasarkan penilaian ekologi ikan famili Chaetodontidae, maka dilakukan penggolongan ikan famili Chaetodontidae berdasarkan nilai skoring kelimpahan ikan Chaetodontidae menurut McMellor (2007), dapat dilihat pada Tabel 2, di bawah ini. 
SPERMONDE (2017) 2(3): 34-42

Tabel 2. Kondisi ikan Chaetodontidae berdasarkan kriteria skoring penilaian ekologi ikan karang pada stasiun penelitian di Kepulauan Spermonde (McMellor, 2007).

\begin{tabular}{lcccc}
\hline \multicolumn{1}{c}{ STASIUN } & KELIMPAHAN & STANDAR KELIMPAHAN & SKOR & KRITERIA \\
\hline P. Kapoposang & 46 & $>8$ & 5 & Sangat Baik \\
P. Lanjukang & 3 & $<4$ & 0 & Sangat Buruk \\
P. Badi & 11 & $>8$ & 5 & Sangat Baik \\
P. Lumu-lumu & 2 & $<4$ & 0 & Sangat Buruk \\
P. Balanglompo & 7 & $>6$ & 3 & Baik \\
P. Karanrang & 1 & $<4$ & 0 & Sangat Buruk \\
\hline
\end{tabular}

Hasil penilaian skoring pada Pulau Kapoposang dan Pulau Badi menunjukkan nilai tertinggi di antara pulau lainnya yang termasuk ke dalam stasiun penelitian, berdasarkan hal tersebut, maka dapat disimpulkan bahwa pada stasiun tersebut kelimpahan dan keragaman jenis ikan Chaetodontidae masih tergolong sangat baik.

\section{Uji ANOSIM dan SIMPER}

Berdasarkan hasil uji One Way Analisys of Similarities (ANOSIM) untuk mengetahui ada tidaknya perbedaan komposisi jenis ikan Chaetodontidae di setiap stasiun pengamatan dan hasil uji Similarity of Percentages (SIMPER) untuk mengetahui jenis apa yang menjadi pembeda di antara stasiun pengamatan di Kepulauan Spermonde, hasilnya dapat dilihat pada Tabel 3.
Berdasarkanhasiluji ANOSIMmenunjukkan nilai $0,373(p<0,05)$ yang berarti bahwa komposisi jenis ikan Chaetodontidae pada daerah Outer Zone-Middle Zone tidak berbeda nyata dengan melihat adanya kesamaan komposisi jenis di kedua zona tersebut, sedangkan pada daerah Outer Zone-Inner Zone dan Middle Zone-Inner Zone menunjukkan nilai yang sama yaitu 0,018 $(\mathrm{p}<0,05)$ yang berarti bahwa komposisi jenis ikan Chaetodontidae berbeda secara nyata pada lokasi tersebut.

Perbedaan komposisi jenis ikan Chaetodontidae di beberapa lokasi penelitian dipengaruhi oleh komposisi struktur dan substrat dasar perairan yang menjadi faktor pembatas keberadaan ikan Chaetodontidae, khususnya tutupan karang hidup yang menjadi makanan utama dari ikan Chaetodontidae sehingga dijadikan sebagai ikan indikator untuk

Tabel 3. Hasil uji One Way Analysis of Similarities (ANOSIM) dan Similarity Percentages (SIMPER) pada stasiun penelitian di Kepulauan Spermonde.

\begin{tabular}{lcccl}
\hline \multicolumn{2}{c}{ ANOSIM } & & & \multicolumn{2}{c}{ SIMPER } \\
\hline $\begin{array}{l}\text { Hubungan Antar } \\
\text { Zona }\end{array}$ & $\begin{array}{c}\text { Global } \\
\mathrm{R}\end{array}$ & $\begin{array}{c}\text { Sig. } \\
\text { Level } \\
(\%)\end{array}$ & $\begin{array}{c}\text { Persentase } \\
\text { Ketidaksamaan } \\
(\%)\end{array}$ & $\begin{array}{c}\text { Taksa yang Mempengaruhi } \\
\text { Perbedaan } \\
(\%)\end{array}$ \\
\hline $\begin{array}{l}\text { Outer Zone-Middle } \\
\text { Zone }\end{array}$ & 0,026 & 37,3 & 89,68 & $\begin{array}{l}\text { Hemitaurichthys polylepis }(22,35) \\
\text { Chaetodon Baronessa }(13,37) \\
\text { Chaetodon octofasciatus }(10,63)\end{array}$ \\
$\begin{array}{l}\text { Outer Zone-Inner } \\
\text { Zone }\end{array}$ & 0,615 & 1,8 & 100 & $\begin{array}{l}\text { Chelmon rostratus }(28,52) \\
\text { Hemitaurichthys polylepis }(20,61)\end{array}$ \\
$\begin{array}{l}\text { Middle Zone-Inner } \\
\text { Zone }\end{array}$ & 0,538 & 1,8 & 100 & $\begin{array}{l}\text { Chaetodon kleinii }(8,57) \\
\text { Chelmon rostratus }(45,34) \\
\text { Chaetodon kleinii }(13,71) \\
\text { Chaetodon octofasciatus }(13,01)\end{array}$ \\
\hline
\end{tabular}


menilai kondisi terumbu karang. Menurut Marsaoli (1998) kelimpahan ikan pemakan karang hidup tinggi dan menurun sejalan dengan besarnya perubahan penutupan karang. Hal ini disebabkan karena penutupan karang hidup yang tinggi menyediakan pakan dalam jumlah banyak sehingga ikan pemakan karang dengan mudah mendapatkan pakan untuk kebutuhan pertumbuhan dan perkembangan populasi.

\section{Uji MDS}

Berdasarkan hasil analisis Multidimensional Scaling (MDS) yang menunjukkan ada tidaknya keterkaitan antara spesies berdasarkan tiga zona di Perairan Spermonde, dapat dilihat pada Gambar 2.

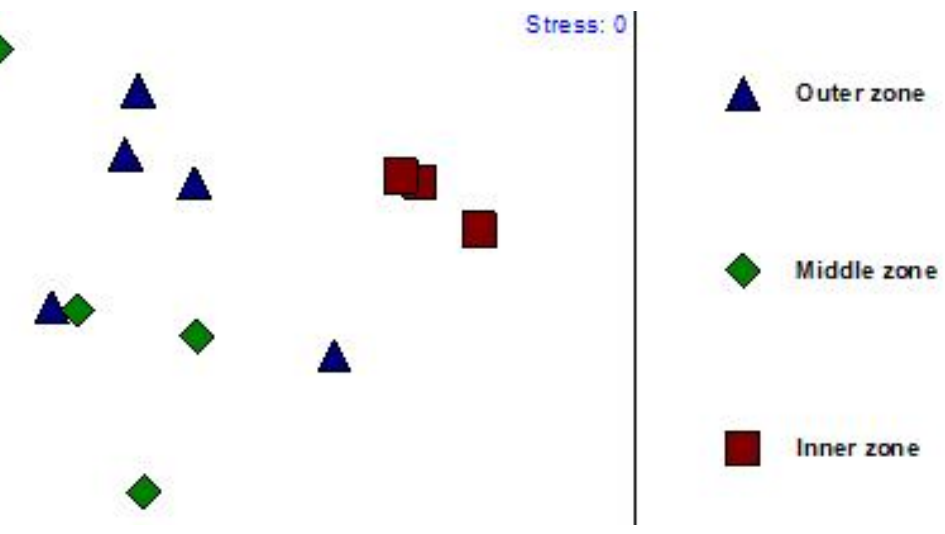

Gambar 2. Keterkaitan jenis Chaetodontidae berdasarkan zona.

Stress value $0,00(<0,05)$ yang menunjukkan plot yang sempurna, artinya kemungkinan tidak ada kesalahan dalam menginterpretasikannya. Model plot di atas menunjukkan adanya keterkaitan berupa kesamaan jenis ikan Chaetodontidae antara outer zone dan middle zone dengan melihat posisi objek yang menunjukkan bahwa beberapa jenis ikan Chaetodontidae pada outer zone terdapat pada middle zone, dan beberapa jenis ikan Chaetodontidae pada middle zone terdapat pada outer zone, adapun jenis Chaetodon tersebut diantaranya Chaetodon kleinii, Chaetodon trifascialis, Chaetodon melanotus, dan Chaetodon trifasciatus. Sedangkan jenis ikan Chaetodontidaepada inner zone tidak terdapat hubungan ataupun kesamaan jenis pada kedua stasiun tersebut dan jenis ikan Chaetodontidae yang terdapat pada inner zone yaitu Chelmon rostratus dan Chaetodon adiergastos.

\section{Kondisi Terumbu Karang}

Tutupan substrat dasar terumbu karang pada enam stasiun penelitian pada stasiun di Kepulauan Spermonde dengan kedalaman berkisar 4-6 meter didominasi oleh live coral, dead coral, dan abiotik.

Berdasarkan Tabel 4, tentang kategori kerusakan terumbu karang menunjukkan bahwa Pulau Badi dan Pulau Karanrang tergolong ke dalam kategori baik $(50,0$ - 74,9) dengan nilai untuk Pulau Badi sebanyak $72,6 \%$ yang didominasi oleh kategori Acropora branching dan Coral massive, sedangkan untuk Pulau Karanrang sebanyak $57,5 \%$ yang didominasi oleh Coral branching dan Coral foliosa. Untuk kategori sedang $(25,0$ - 49,9) terdapat pada Pulau Kapoposang dan Pulau Lumu-lumu dengan nilai untuk Pulau Kapoposang sebanyak 41,8\% yang didominasi oleh kategori Coral encrusting dan Coral massive, sedangkan untuk Pulau Lumu-lumu sebanyak 30,6\% yang didominasi oleh kategori Acropora branching dan Coral foliosa. Untuk kategori Buruk $(0,0$ - 24,9) terdapat pada Pulau Lanjukang dan Balanglompo dengan nilai untuk Pulau Lanjukang sebanyak 8,5\% yang didominasi oleh kategori Coral branching dan Coral massive,

Tabel 4. Kategori penilaian kondisi kerusakan terumbu karang pada stasiun penelitian di Kepulauan Spermonde.

\begin{tabular}{lcccccc}
\hline \multicolumn{1}{c}{ Stasiun } & Live Coral & Dead Coral & Algae & Other & Abiotik & Kategori \\
\hline St.1 Kapoposang & 41,8 & 44,2 & 0 & 3,2 & 10,8 & Sedang \\
St.2 Lanjukang & 8,5 & 1,3 & 0 & 1,3 & 88,9 & Buruk \\
St.3 Badi & 72,6 & 17,4 & 0 & 1,2 & 8,6 & Baik \\
St.4 Lumu-lumu & 30,6 & 63,2 & 0 & 6,2 & 0 & Sedang \\
St.5 Balanglompo & 5 & 5,8 & 6 & 5,5 & 77,7 & Buruk \\
St.6 Karanrang & 57,5 & 36,7 & 0 & 3,3 & 2,5 & Baik \\
\hline
\end{tabular}


sedangkan untuk Pulau Balanglompo sebanyak $5 \%$ yang didominasi oleh kategori Coral massive dan Soft coral.

Kerusakan terumbu karang di Pulau Balanglompo disebabkan oleh aktivitas kapal yang membuang jangkar kapal di sembarang tempat di Pulau Balanglompo mengingat Pulau Balanglompo memiliki Dermaga yang cukup banyak dan besar sehingga banyak kapal baik yang berukuran kecil maupun yang besar lalu lalang ke tempat tersebut.

Direktorat Konservasi, Pulau-pulau Kecil dan Taman Nasional Laut (2006) menyatakan bahwa aktivitas lempar jangkar di daerah terumbu karang juga memberikan kontribusi cukup besar dalam kerusakan terumbu karang. Nelayan dan wisatawan seringkali menambatkan jangkar perahunya pada terumbu karang. Jangkar yang dijatuhkan dan ditarik di antara terumbu karang maupun hempasan nantinya sangat merusak koloni terumbu karang. Jika setiap hari ada 20 buah kapal yang menambatkan jangkar pada terumbu karang selama 200 hari dalam setahun, maka ratusan meter persegi terumbu karang akan rusak. Pulau Lanjukang, rusaknya karang disebabkan oleh aktivitas pengeboman dan pembiusan ikan yang marak terjadi di lokasi tersebut.

Berdasarkan hasil uji korelasi Spearman yang menggambarkan ada tidaknya hubungan kelimpahan ikan Chaetodontidae dengan persentase tutupan terumbu karang di Kepulauan Spermonde, dapat dilihat pada Gambar 3.

Berdasarkan hasil uji korelasi Spearman menunjukkan nilai sebesar 0,872 yang menunjukkan nilai yang tidak signifikan (tidak berbeda nyata) dan pada Gambar 3, di atas menunjukkan nilai $\mathrm{R} 2=0,273$ yang berarti bahwa terdapat hubungan yang tidak linear antara kelimpahan ikan Chaetodontidae dengan persentase tutupan terumbu karang di Perairan Spermonde. Dengan demikian dapat dikatakan bahwa persentase penutupan karang hidup memiliki hubungan yang lemah terhadap kelimpahan ikan Chaetodontidae. Sama halnya dengan penelitian yang dilakukan oleh Prasetyanda (2011) di Perairan Pasir Putih, Situbondo yang menyatakan bahwa korelasi antara tutupan karang dengan kelimpahan ikan famili Chaetodontidae didapatkan hasil tidak adanya korelasi dimana kelimpahan ikan tidak dipengaruhi oleh tutupan karang, namun Berbeda halnya dengan hasil yang didapatkan oleh Titaheluw (2011) di Perairan Sidodadi Pulau Tegal Teluk Lampung dan Suharti (2012) di Pulau Karang Kepulauan Seribu yang menunjukkan ikan Chaetodontidae berkorelasi positif dengan terumbu karang.

Pada beberapa stasiun penelitian seperti pada Pulau Badi yang menunjukkan adanya korelasi positif antara kelimpahan ikan Chaetodontidae terhadap tutupan karang dengan bentuk pertumbuhan tertentu, dimana tutupan karang hidup yang mendominasi yaitu Acropora branching (22\%) dan Coral massive $(11,02 \%)$ dan terdapat 8 jenis ikan Chaetodontidae dengan jumlah individu sebanyak 11 individu. Hal tersebut diperjelas penelitian yang dilakukan oleh Arsyad (2016) di Pulau Badi yang menemukan sebanyak 13 jenis ikan Chaetodontidae dan tutupan karang sebanyak $25,65 \%$ sampai $58,93 \%$ menyatakan bahwa kelimpahan ikan Chaetodontidae berkaitan erat dengan persentase tutupan habitat kategori karang bercabang (branching).

Namun pada beberapa stasiun seperti Pulau

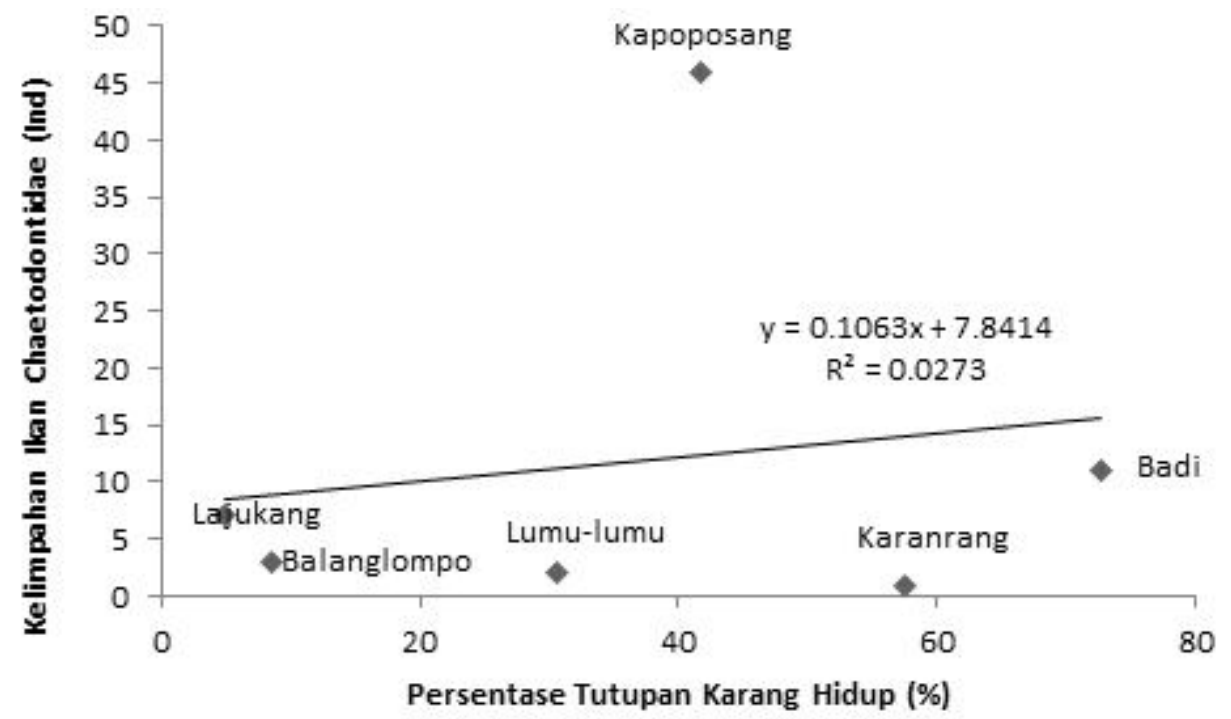

Gambar 3. Hubungan kelimpahan ikan Chaetodontidae dengan persentase tutupan karang hidup pada stasiun penelitian di Kepulauan Spermonde. 
Karanrang yang menunjukkan nilai tutupan sebanyak 51,71\% (Kategori Baik) namun hanya memiliki 1 jenis dan 1 individu ikan Chaetodontidae. Hal tersebut dapat dilihat dari komposisi substrat dasar yang mendominasi yaitu Dead coral algae $(36,7 \%)$ dan substrat karang hidup yang didominasi oleh Coral branching $(25,9 \%)$, meskipun kategori kesehatan terumbu karang pada Pulau Karanrang tergolong ke dalam kategori baik, namun bila dilihat dari komposisi susunan substrat karang hidupnya yaitu karang non Acropora dan tidak terdapat karang Acropora pada stasiun pengamatan, sedangkan kecenderungan ikan Chaetodontidae lebih tertarik pada karang Acropora.

Hal yang sama juga didapatkan Williams pembiusan pada stasiun tersebut.

\section{Kualitas Perairan di Kepulauan Spermonde}

Pada penelitian yang dilakukan pada enam stasiun pengamatan di Kepulauan Spermonde, pengukuran parameter kualitas perairan dilakukan secara in situ.Untuk hasil pengukuran suhu perairan pada stasiun penelitian di Kepulauan Spermonde berkisar antara 29,7$31,23^{\circ} \mathrm{C}$, sedangkan nilai salinitas berkisar antara

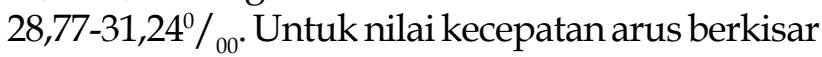
antara 0,12 m/detik-0,64 m/detik, sedangkan $\mathrm{pH}$ berkisar 7,9-8,19. Hasil pengukuran parameter kualitas perairan pada Tabel 5, menunjukkan kisaran yang optimal berdasarkan standar baku mutu air laut untuk kehidupan biota laut yang

Tabel 5. Nilai rata-rata ( \pm standar error) parameter kualitas perairan pada stasiun penelitian di Kepulauan Spermonde.

\begin{tabular}{|c|c|c|c|c|c|}
\hline STASIUN & $\begin{array}{c}\text { TITIK } \\
\text { KOORDINAT }\end{array}$ & SUHU $\left({ }^{\circ} \mathrm{C}\right)$ & $\begin{array}{c}\text { SALINITAS } \\
(\%)\end{array}$ & $\begin{array}{l}\text { KECEPATAN } \\
\text { ARUS (m/det) }\end{array}$ & pH \\
\hline P. Kapoposang & $\begin{array}{l}\text { E. } 118^{0} 96^{\prime} 328^{\prime \prime} \\
\text { S. } 04^{0} 65^{\prime} 546^{\prime \prime}\end{array}$ & $29,83 \pm 0,00$ & $29,10 \pm 0,04$ & $0,24 \pm 0,06$ & $8,05 \pm 0,003$ \\
\hline P. Lanjukang & $\begin{array}{l}\text { E. } 119^{0} 08^{\prime} 361^{\prime \prime} \\
\text { S.04 } 04^{0} 97^{\prime} 795^{\prime \prime}\end{array}$ & $30,70 \pm 0,04$ & $31,03 \pm 0,01$ & $0,23 \pm 0,02$ & $8,05 \pm 0,003$ \\
\hline P. Lumu-lumu & $\begin{array}{l}\text { E. } 119^{0} 20^{\prime} 790^{\prime \prime} \\
\text { S. } 04^{\circ} 97^{\prime} 984^{\prime \prime}\end{array}$ & $30,60 \pm 0,02$ & $31,24 \pm 0,10$ & $0,64 \pm 0,02$ & $8,01 \pm 0,03$ \\
\hline P. Badi & $\begin{array}{l}\text { S. } 04^{0} 97^{\prime} 152^{\prime \prime} \\
\text { E. } 119^{0} 28^{\prime} 375^{\prime \prime}\end{array}$ & $30,58 \pm 0,01$ & $31,00 \pm 0,05$ & $0,12 \pm 0,01$ & $8,19 \pm 0,03$ \\
\hline P. Karanrang & $\begin{array}{l}\text { E. } 119^{0} 37^{\prime} 686^{\prime \prime} \\
\text { S. } 04^{0} 85^{\prime} 257^{\prime \prime}\end{array}$ & $29,70 \pm 0,02$ & $30,07 \pm 0,10$ & $0,16 \pm 0,01$ & $7,90 \pm 0,08$ \\
\hline P. Balanglompo & $\begin{array}{l}\text { E. } 119^{0} 39^{\prime} 709^{\prime \prime} \\
\text { S. } 04^{0} 93^{\prime} 822^{\prime \prime}\end{array}$ & $31,23 \pm 0,07$ & $28,77 \pm 0,01$ & $0.26 \pm 0,01$ & $8,11 \pm 0,01$ \\
\hline
\end{tabular}

(1982) yang menemukan ikan dari famili Chaetodontidae yang lebih kaya jenisnya pada daerah terumbu karang yang didominasi oleh jenis karang Acropora (Acropora palifera dan Acropora hyachyntus yang merupakan tipe karang bercabang panjang) di Great Barrier Reef bagian tengah. Selain itu Bouchon-Navaro et al. (1985) menyatakan bahwa kehilangan tipe karang bercabang panjang di Tiahura (Acropora cytherea) pada rataan terumbu karang penghalang, dan koloni Acropora dan Pocillopora di lereng terumbu luar menurunkan kepadatan ikan Chaetodontidae.

Selain itu faktor lain yang menjadi penyebab kurangnya kelimpahan ikan dari stasiun tersebut yaitu maraknya aktivitas penangkapan ikan yang tidak ramah lingkungan seperti pengeboman dan tertera pada Keputusan Menteri Lingkungan Hidup No. 51 Tahun 2004.

\section{KESIMPULAN}

Jenis Chaetodontidae yang didapatkan pada stasiun penelitian di Kepulauan Spermonde tercatat 16 jenis dari 5 genera dan jumlah sebanyak 70 individu. Kelimpahan ikan Chaetodontidae yang tertinggi terdapat pada Pulau Kapoposang sebanyak 46 individu dan kelimpahan terendah terdapat pada Pulau Karanrang sebanyak 1 individu.

Persentase tutupan karang hidup pada stasiun penelitian di Kepulauan Spermonde didapatkan hasil yang bervariasi untuk kategori baik terdapat pada Pulau Badi (72,6\%) dan 
Pulau Karanrang $(57,5)$, untuk kategori sedang terdapat pada Pulau Kapoposang (41,8\%) dan Pulau Lumu-lumu (30,6\%), sedangkan untuk Kategori buruk terdapat pada Pulau Lanjukang(8,5\%) dan Pulau Balanglompo (5\%) .

Keragaman jenis ikan Chaetodontidae tinggi pada stasiun yang didominasi oleh karang Acropora branching (ACB). Kelimpahan dan keragaman jenis ikan Chaetodontidae tidak memiliki hubungan yang kuat terhadap persentase tutupan karang hidup pada stasiun penelitian di Kepulauan Spermonde. Namun pada stasiun tertentu seperti pada Pulau Badi memiliki korelasi positif antara persentase tutupan karang hidup dengan kelimpahan ikan Chaetodontidae.

\section{DAFTAR PUSTAKA}

Allen, GR, M. Allen and R. Steene. 1998. A Guide to Angelfish and Butterflyfish. Odyssey Publishing (USA). Tropical Reef Research. Australia.

Arsyad, N.M.,2016. Komposisi Jenis dan Sebaran Ikan Indikator Famili Chaetodontidae Kaitannya dengan Tutupan Habitat Terumbu Karang di Pulau Badi, Kepuluan Spermonde. Skripsi. Jurusan Ilmu Kelautan dan Perikanan. Fakultas Ilmu Kelautan dan Perikanan. Universitas Hasanuddin. Makassar.

Bouchon-Navaro Y., C. Bouchon, and M. L. Harmelin-Vivien. 1985. Impact of Coral Degradation on a Chaetodontid Fish Assemblage (Moorea, French Polynesia). In: Proceedings of the Fifth International Coral Reef Congress, Tahiti, 5: 427-432.

Clarke, K.R. and Warwick, R.M. 2001. Change in Marine Communities: An Approach to Statistical Analysis and Interpretation. $2^{\text {nd }}$ Edition. PRIMER-5.Plymouth Marine Laboratory, UK.

Direktorat Konservasi, Pulau-pulau Kecil dan Taman Nasional Laut. 2006. Pedoman Pelaksanaan Transplantasi Karang. Jakarta: Departemen Kelautan dan Perikanan

English, S., C. Wilkinson, and U. Baker (eds). 1994. Survey Manuals for Tropical Marine Resources. Australia Institute of Marine Science. Townsville. Australia.

Hukom, F.D. 2001. Asosiasi Antara Komunitas
Ikan Karang (Family Chaetodontidae) dengan Bentuk Pertumbuhan Karang di Perairan Kepulauan Derawan Kalimantan Timur. Pusat Penelitian Dan Pengembangan Oseonologi, LIPI. Jakarta

Keputusan Menteri Lingkungan Hidup Nomor 51 Tahun 2004 Tentang Baku Mutu Air Laut

Kuiter, R H. and Tonozuka, T. 2001. Pictorial Guide to; Indonesia Reef Fishes. Zoonetics. Australia.

Marsaoli, MK. 1998. Hubungan Persentase Penutupan Karang Hidup dengan Densitas Beberapa Jenis Ikan Karang di Perairan Kepulauan Karimunjawa, Jepara. Tesis. Institut Pertanian Bogor. Bogor

McMellor, S. 2007. A Conservation Value Index to Facilitate Coral Reef Evaluation and Assesmant. Thesis Submitted for the Degree of Doctor of Philosophy. Department of Biological Sciences, University of Essex, UK.

Nontji, A. 2005. Laut Nusantara. Jakarta: Penerbit Djambatan.

Odum, E. P. 1971. Dasar-dasar Ekologi. Catatan ke-3. Gajah Mada University Press. Yogyakarta.

Prasetyanda I.M. 2011. Korelasi Tutupan Terumbu Karang dengan Kelimpahan Relatif Ikan Famili Chaetodontidae di Perairan Pantai Pasir Putih, Situbondo. Skripsi. Institut Teknologi Sepuluh November. Surabaya.

Sudjana (1996). Metoda Statistika. Edisi ke-6. Bandung: Tarsito

Suharti, R, 2012. Hubungan Kondisi Terumbu Karang Dengan Kelimpahan Ikan Chaetodontidae di Pulau Karang Bangkok Kepulauan Seribu. Tesis. Universitas Terbuka. Jakarta.

Titaheluw,S.S.2011.Keterkaitan Antara Terumbu Karang dengan Ikan Chaetodontidae: Implikasi Untuk Pengelolaan. Tesis.Institut Pertanian Bogor. Bogor.

Williams, D. McB., 1982. Patterns in the Distribution of Fish Communities across the Central Great Barrier Reef. Coral Reef. 1:35-43. 